\title{
Nanoparticles for hyperthermic therapy: synthesis strategies and applications in glioblastoma
}

This article was published in the following Dove Press journal:

International Journal of Nanomedicine

10 June 2014

Number of times this article has been viewed

\author{
Jyoti Verma ${ }^{1,2}$ \\ Sumit Lal' \\ Cornelis JF Van Noorden ${ }^{3}$ \\ 'Department of Medicine, Harvard \\ Medical School, ${ }^{2}$ Division of \\ Endocrinology, Diabetes and \\ Hypertension, Brigham and \\ Women's Hospital, Boston, MA, USA; \\ ${ }^{3}$ Department of Cell Biology and \\ Histology, Academic Medical Centre, \\ University of Amsterdam, Amsterdam, \\ The Netherlands
}

\begin{abstract}
Glioblastoma multiforme (GBM) is the most common and most aggressive malignant primary brain tumor in humans. Current GBM treatment includes surgery, radiation therapy, and chemotherapy, sometimes supplemented with novel therapies. Despite recent advances, survival of GBM patients remains poor. Major challenges in GBM treatment are drug delivery across the blood-brain barrier, restriction of damage to healthy brain tissues, and limitation of resistance to therapies. This article reviews recent advances in the application of magnetic nanoparticles (MNPs), gold nanorods (GNRs), and carbon nanotubes (CNTs) for hyperthermia ablation of GBM. First, the article introduces GBM, its current treatment, and hyperthermia as a potential modality for the management of GBM. Second, it introduces MNPs, GNRs, and CNTs as inorganic agents to induce hyperthermia in GBM. Third, it discusses different methodologies for synthesis of each inorganic agent. Finally, it reviews in vitro and in vivo studies in which MNPs, GNRs, and CNTs have been applied for hyperthermia ablation and drug delivery in GBM.
\end{abstract}

Keywords: hyperthermia, targeted drug delivery, SPIONs, gold nanorods, carbon nanotubes

\section{Introduction}

\section{Glioblastoma multiforme}

Gliomas are heterogeneous central nervous system tumors. ${ }^{1}$ Glioblastoma multiforme (GBM) is the most frequent and malignant type of glioma, and despite advances in diagnosis and treatment of GBM, median survival of GBM patients remains less than 15 months. $^{2}$ There are at least two factors that make GBM treatment extremely difficult. First, the brain has limited capacity to repair itself. Second, GBM is highly invasive and resistant to therapies. ${ }^{3}$

Conventional GBM therapies consist of surgery, radiotherapy (RT), and chemotherapy. Objectives of surgery range from merely confirmation of the diagnosis or alleviation of symptoms due to mass effects to aggressive attempts to improve quality of life and prolong survival of the patient. ${ }^{3}$ RT is one of the oldest and most common treatment options for GBM patients. It is based on generation of electrons and free radicals by ionizing radiation to damage deoxyribonucleic acid (DNA). Early clinical trials revealed a modest, yet undeniable efficacy of RT in treating GBM. However, there are several limitations of RT including risk of necrosis, permanent neuronal damage, and radio resistance of certain tumor types (Figure 1). ${ }^{4}$

Temozolomide has been the mainline chemotherapy drug for GBM treatment for over 10 years. ${ }^{5}$ Temozolomide, an oral alkylating agent, is a second-generation imidazotetrazine derivative, which exhibits cytotoxic effects by methylation of specific DNA sites. ${ }^{5}$
Correspondence: Sumit Lal Department of Medicine, Harvard Medical School, 22I Longwood Ave, Boston, MA 02115 , USA

Email slal@research.bwh.harvard.edu 


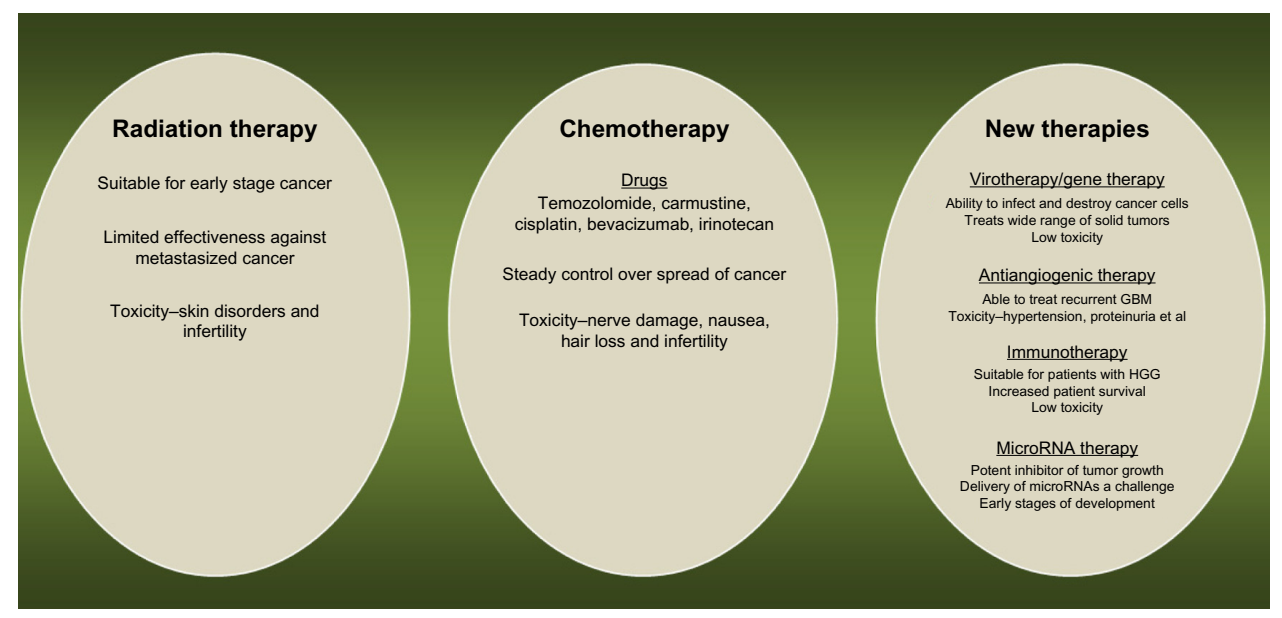

Figure I Current treatment options for glioblastoma multiforme patients.

Abbreviations: GBM, glioblastoma multiforme; HGG, high-grade glioma; RNA, ribonucleic acid.

Bevacizumab is often used as adjuvant therapy for GBM treatment. It is a humanized monoclonal antibody against vascular endothelial growth factor that act as angiogenesis inhibitor. ${ }^{6}$ Side effects of chemotherapy are often severe, including nerve damage, nausea, hair loss, and infertility (Figure 1). Chemotherapy in combination with other therapies, especially RT, provides the most effective treatment strategy for GBM at the moment. ${ }^{5}$ For instance, a Phase III study conducted by the European Organization for Research and Treatment of Cancer and the National Cancer Institute of Canada reported that combined therapy of RT and temozolomide increased median survival time significantly when compared with RT alone. ${ }^{7}$ The 5-year overall survival rate was $9.8 \%$ for the combination therapy group versus $1.9 \%$ for the RT alone group, with a median follow-up of 61 months. This and other studies are paving the way toward new treatment combinations.

\section{Hyperthermia}

Hyperthermia is a fairly new concept that finds its application in the treatment of different types of cancers and is based on generation of heat at the tumor site. This results in changes in the physiology of diseased cells, finally leading to apoptosis. ${ }^{8}$

Hyperthermia treatment mechanisms involve intracellular heat stress in the temperature range of $41^{\circ} \mathrm{C}-46^{\circ} \mathrm{C}$, resulting in activation and/or initiation of many intracellular and extracellular degradation mechanisms. The intracellular and extracellular effects of hyperthermia include protein misfolding and aggregation, alteration in signal transduction, induction of apoptosis, changes in potential of hydrogen $(\mathrm{pH})$, and reduced perfusion and oxygenation of the tumor. ${ }^{8}$
The effectiveness of hyperthermia treatment greatly depends on the temperature profile at the targeted tumor site, duration of exposure, and characteristics of cancer cells. ${ }^{9,10}$ Traditionally, hyperthermia treatment was performed using external devices to transfer thermal energy to cancerous tissues, either by irradiation with light or electromagnetic waves. Conventional techniques for induction of hyperthermia are ultrasound, microwaves, infrared irradiation, and tubes with hot water. However, each of these methods suffers from limitations (Table 1), ${ }^{10}$ including low penetration of heat in the tumor; excessive heating of healthy tissue; thermal under-dosage in the target region; and dissipation of heat by the blood, which is especially a problem in well-vascularized tumors..$^{10,11}$

To overcome these limitations, magnetic materials were first proposed for hyperthermia treatment of cancer in $1957 .{ }^{12}$ Many approaches have evolved since then to develop a new therapeutic system called magnetic hyperthermia therapy (MHT). MHT is based on generation of heat by magnetic nanoparticles (MNPs) when exposed to alternating magnetic fields. When MNPs are injected in the tumor and an alternating magnetic field is applied, the tumor temperature rises and results in thermal ablation of tumor cells. ${ }^{13}$ MHT encompasses many salient features including externally-stimulated intracellular heating, delivery through multiple routes, potential to cross the blood-brain barrier, and antitumoral immunity. ${ }^{13,14}$

\section{Nanoparticle-based hyperthermia MNPs}

In the last decade, several types of iron oxides have been explored to synthesize MNPs, including magnetite $\left(\mathrm{Fe}_{3} \mathrm{O}_{4}\right)$, hematite $\left(\alpha-\mathrm{Fe}_{2} \mathrm{O}_{3}\right)$, and maghemite $\left(\gamma-\mathrm{Fe}_{2} \mathrm{O}_{3}\right.$ and $\left.\beta-\mathrm{Fe}_{2} \mathrm{O}_{3}\right){ }^{15}$ MNPs are the most frequently investigated nanoparticles for 
Table I Types of hyperthermia therapy in cancer treatment

\begin{tabular}{|c|c|c|c|}
\hline Hyperthermia type & Delivery mode & Advantages & Disadvantages \\
\hline Thermal conduction & Heated water & None & Heat penetration up to $3-5 \mathrm{~mm}$ \\
\hline Radiation hyperthermia & Lower frequency waves & Moderate penetration & Hyperthermia of healthy tissues \\
\hline Magnetic induction hyperthermia & Magnetic field & Deep penetration & $\begin{array}{l}\text { Toroidal heating pattern and } \\
\text { low magnetic energy absorption }\end{array}$ \\
\hline Ultrasound power deposition & Pressure waves & $\begin{array}{l}\text { Optimization of penetration } \\
\text { by modulating frequency }\end{array}$ & $\begin{array}{l}\text { Limited application in anatomic } \\
\text { body locations }\end{array}$ \\
\hline
\end{tabular}

biomedical applications because of their biocompatibility. ${ }^{15}$ Among MNPs, superparamagnetic iron oxide nanoparticles (SPIONs) are the nanoparticles of choice due to their unique optical and magnetic properties, such as high paramagnetism, coercivity, magnetic susceptibility, and low Curie temperature. ${ }^{16}$

Coercivity and Curie temperature are two important properties for nanoparticles. Coercivity of ferromagnetic material is a measure of intensity of the applied magnetic field that is required to reduce the magnetization of a material to zero. ${ }^{17}$ Thus, coercivity measures the resistance of ferromagnetic material to demagnetize. Curie temperature is the temperature where the permanent magnetism of material changes to induced magnetism. When the Curie temperature is known, overheating of tumor tissue can be avoided, and thus side effects on healthy tissue can be limited. ${ }^{18}$ Preliminary studies have suggested that MHT has potential to be applied for treatment of GBM. In fact, SPIONs have shown uniform intratumoral distribution and controlled heating of GBM without major side effects. ${ }^{19}$

For the application of MNPs in MHT, their physical and chemical properties need to be optimized, which is a technological challenge. The next section discusses strategies for synthesis of different types of MNPs.

\section{Methods for the synthesis of MNPs}

Methods that are most commonly used for MNP synthesis are chemical coprecipitation, thermal decomposition, and microemulsion (Figure 2). Other less commonly used methods include hydrothermal synthesis, sonochemical synthesis, and electrochemical synthesis. ${ }^{20}$ Control of size, stability, biocompatibility, and monodispersion of nanoparticles are some of the most important factors to consider before selecting a synthesis route. ${ }^{20}$ The three most commonly used methods to synthesize MNPs are discussed here.

\section{Chemical coprecipitation}

In this method, hydrolysis of a mixture of $\mathrm{Fe}^{2+}$ and $\mathrm{Fe}^{3+}$ ions in 2:1 molar ratio is carried out under inert atmosphere. Ferrous and ferric ions are mixed in a 2:1 molar ratio at $\mathrm{pH}$ 8-14. Magnetite precipitates after being formed according to the following reaction:

$$
\mathrm{Fe}^{2+}+2 \mathrm{Fe}^{3+}+8 \mathrm{OH}^{-} \rightarrow \mathrm{Fe}_{3} \mathrm{O}_{4}+4 \mathrm{H}_{2} \mathrm{O}
$$

Structural characteristics, such as size, dispersion, and morphology, of MNPs mainly depend on the type of salts

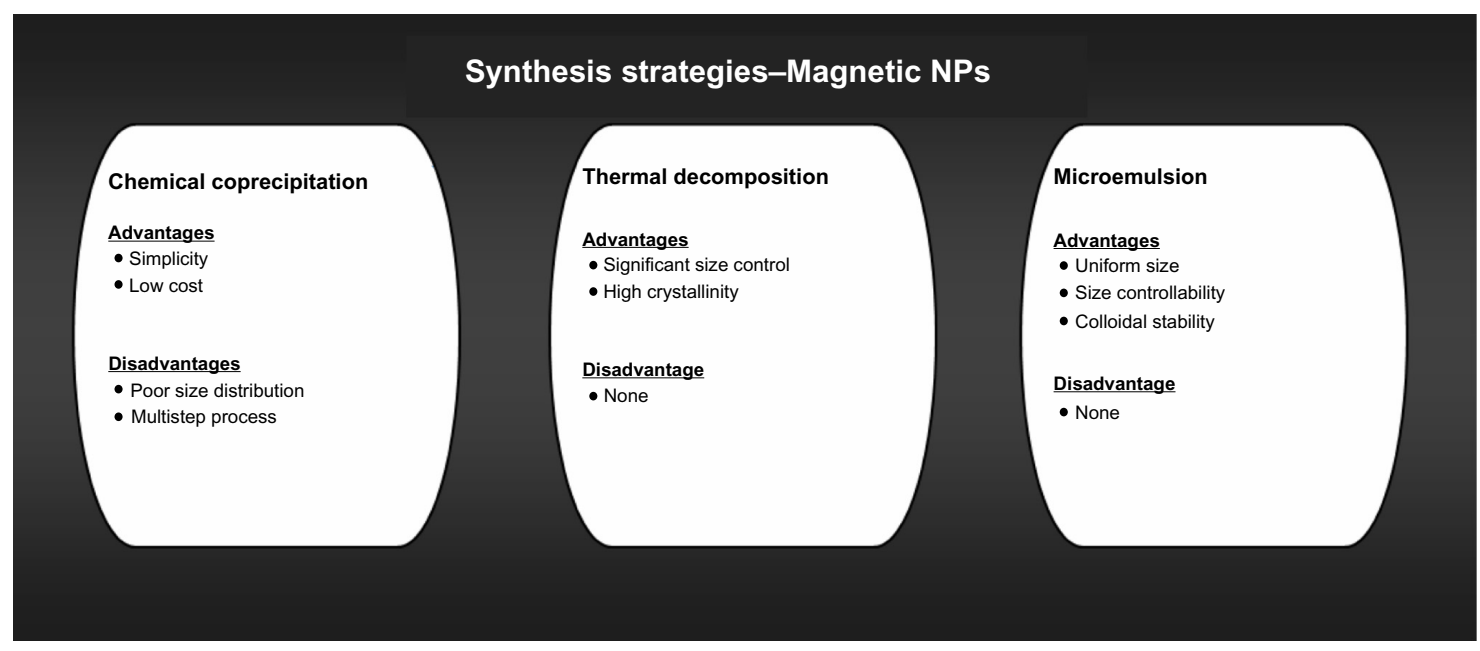

Figure 2 Methods for the synthesis of magnetic nanoparticles. Abbreviation: NPs, nanoparticles. 
used, the ratio of ferric and ferrous ions, and the reaction temperature. ${ }^{21}$ Coprecipitation synthesis involves two major steps: first, formation of nuclei and second, growth of nuclei. The advantage of coprecipitation synthesis is the possibility to synthesize industrial quantities of nanoparticles. Large size distribution is the most common problem associated with coprecipitation. To overcome this problem reaction conditions are varied, such as $\mathrm{pH}$, temperature, nature and origin of salts, and the $\mathrm{Fe}^{3+} / \mathrm{Fe}^{2+}$ ratio. ${ }^{21,22}$

\section{Thermal decomposition}

Thermal decomposition is carried out in an organic solution and results in formation of monodispersed iron oxide nanoparticles, with significant size control and crystallinity. Thermal decomposition involves decomposition of iron complexes in the presence of surfactants and organic solvents at high temperatures. ${ }^{23}$

Sun and $Z_{\text {hang }}{ }^{24}$ prepared SPIONs using thermal decomposition. Reactions of iron (III) acetylacetonate were performed at a high temperature $\left(265^{\circ} \mathrm{C}\right)$ in the presence of phenyl ether, alcohol, oleic acid, and oleylamine to form SPIONS with a diameter of $4 \mathrm{~nm}$. Hyeon et $\mathrm{al}^{25}$ synthesized SPIONs with a diameter of 7-25 nm by thermal decomposition. In their study, nanoparticles were synthesized as iron oleate complexes from iron pentacarbonyl by decomposition in the presence of octyl ether and oleic acid at $100^{\circ} \mathrm{C}$. Park et $\mathrm{al}^{26}$ used iron salt (iron chloride $\left[\mathrm{FeCl}_{3} \cdot 6 \mathrm{H}_{2} \mathrm{O}\right]$ ) instead of toxic ferrous metallic compounds as precursor to form an iron-oleic complex. Iron-oleic complexes yielded monodispersions of iron oxide crystals when mixed with sodium oleate in the presence of 1-octadecene and aged for 30 minutes.

\section{Microemulsion}

Iron oxide nanoparticles generated in the presence of microemulsions yield nanoparticles of uniform size and colloidal stability. Inouye et al were the first to synthesize MNPs in microemulsion by oxidation of $\mathrm{Fe}^{2+}$ salts, and the size of MNPs was controlled by varying temperature and surfactant concentration. ${ }^{27}$ Micelles have been immensely useful in synthesizing monodispersed, size-controlled nanoparticles. Lee et al used reverse micelles (micelles with head groups in the center and tails at the periphery) for the synthesis of SPIONs. ${ }^{28}$ This method to generate monodispersed SPIONs is efficient, inexpensive, and large-scale, and it involves synthesis of MNPs at high temperatures using iron salts, surfactant, and solvents in varying concentrations or proportions. $^{28}$

\section{Methods for the surface modification of MNPs}

MNPs are susceptible to corrosion. The most common form of corrosion that occurs in MNPs is oxidation, which leads to loss of magnetism and dispersibility of nanoparticles, thus affecting their ability to induce hyperthermia. Therefore it is necessary to protect MNPs from oxidation. Methods that have been explored to protect MNPs against oxidation include surface modification by surface passivation, surfactant and polymer coating, and metal, silica, and carbon coating. A detailed review on this topic has already been published. A brief overview of methods for surface modification of MNPs is presented below.

\section{Surface passivation by mild oxidation}

Surface passivation is the protection of any material from external environmental factors, and surface passivation by mild oxidation has been used for protecting MNPs. ${ }^{29,30}$ Peng et al used plasma gas condensation to oxidize cobalt nanoparticles in gas phase. ${ }^{29}$ Bönnemann et al used controlled air atmosphere to oxidize cobalt nanoparticles, and this resulted in the formation of an outer layer of cobalt oxide on the nanoparticle and protected it from further oxidation. $^{30}$

\section{Surfactant and polymer coating}

MNPs synthesized through coprecipitation carry negatively charged surfaces, causing them to agglomerate. Surfactants and polymers have been peptized, chemically anchored, or physically adsorbed on MNPs to form stable colloids. ${ }^{31-33}$ These stable colloids create repulsive forces to balance the magnetic and the van der Waals attractive forces acting on the nanoparticles, thus preventing nanoparticles from agglomeration. Polymers that have been used for the formation of stable colloids are poly(pyrrole), poly(aniline), poly(alkyl cyanoacrylates), poly(methylidene malonate), poly(lactic acid), poly (glycolic acid), and poly(e-caprolactone). ${ }^{34-37}$

\section{Metal, silica, and carbon coating}

Precious metals deposited onto MNPs protect the magnetic nanoparticle core from oxidation. Of all precious metals, gold is the metal of choice for coating MNPs due to its low reactivity. However, direct coating of gold onto MNPs is difficult because of the dissimilar nature of the two surfaces. ${ }^{38,39}$ Despite this complication, many researchers have been able to coat MNPs with gold by using new techniques. Ban et al synthesized gold-coated iron nanoparticles using a partial replacement reaction in a polar aprotic solvent, ${ }^{40}$ Liu et al synthesized gold-coated iron nanoparticles using a 
reverse microemulsion method, ${ }^{41}$ and Zhang et al synthesized iron (core) gold (shell) nanoparticles using a combination of wet chemistry and laser irradiation. ${ }^{42}$

\section{Gold nanorods}

Gold nanorods (GNRs) exhibit optical properties that depend on size and aspect ratio. Surface plasmon resonance is the most important property of GNRs. It is a result of interaction between electrons in a conduction band of gold atoms and electric field components of incident electromagnetic radiation. ${ }^{43}$ As a result of surface plasmon resonance, GNRs emit heat upon irradiation with an infrared laser. This property was used in numerous studies to develop photodynamic therapy for GBM treatment. ${ }^{44}$ The most efficient strategies for the synthesis of GNRs of different aspect ratios and sizes are discussed here.

\section{Methods for the synthesis of GNRs}

GNRs can be synthesized by either wet or dry chemistry. Wet chemistry is the preferred mode of synthesis because of its simplicity and low costs. ${ }^{45}$ In the following subsections, three major synthesis methods are reviewed: the template method, the electrochemical method, and the seed-mediated growth method (Figure 3).

\section{Template method}

The template method for synthesis of GNRs involves electrochemical deposition of gold onto the pores of an alumina template membrane or nanoporous polycarbonate. The method was originally used to prepare microscopic electrodes by depositing gold onto a polycarbonate membrane using electroplating. Genzel et al were the first to successfully employ the template method for the synthesis of GNRs. ${ }^{46}$

The method involves four steps. In the first step, copper is sputtered onto an alumina template. In the second step, gold is electrodeposited onto the nanosized pores of alumina. In the third step, the alumina membrane and copper film are dissolved in the presence of an appropriate stabilizer. In the final step, GNRs are dispersed in water or an organic solvent using ultrasonic waves or agitation. GNRs of various diameters and lengths have been successfully generated using the template method. The diameter of nanorods is controlled by the pore diameter of the template, and the length is controlled by the quantity of gold deposited within the membrane nanopores. ${ }^{45}$

\section{Electrochemical method}

The electrochemical method is the most commonly used method for the synthesis of transition metal clusters in an organic solvent. Nikoobakht et al developed the application of an electrochemical method for the synthesis of GNRs and synthesized GNRs in high yields. ${ }^{47}$ The actual synthesis was conducted in an electrochemical cell containing two electrodes. In the cell, a gold metal plate was used as anode, and a platinum plate was used as cathode. The final electrolysis was carried out in the presence of a hydrophilic cationic surfactant and a controlled current mode for 30-60 minutes to successfully synthesize GNRs. ${ }^{47}$

A recent study used a silver plate to control the aspect ratio of GNRs. ${ }^{48}$ Silver metal reacted with gold ions to generate silver ions at the anode. The amount of silver

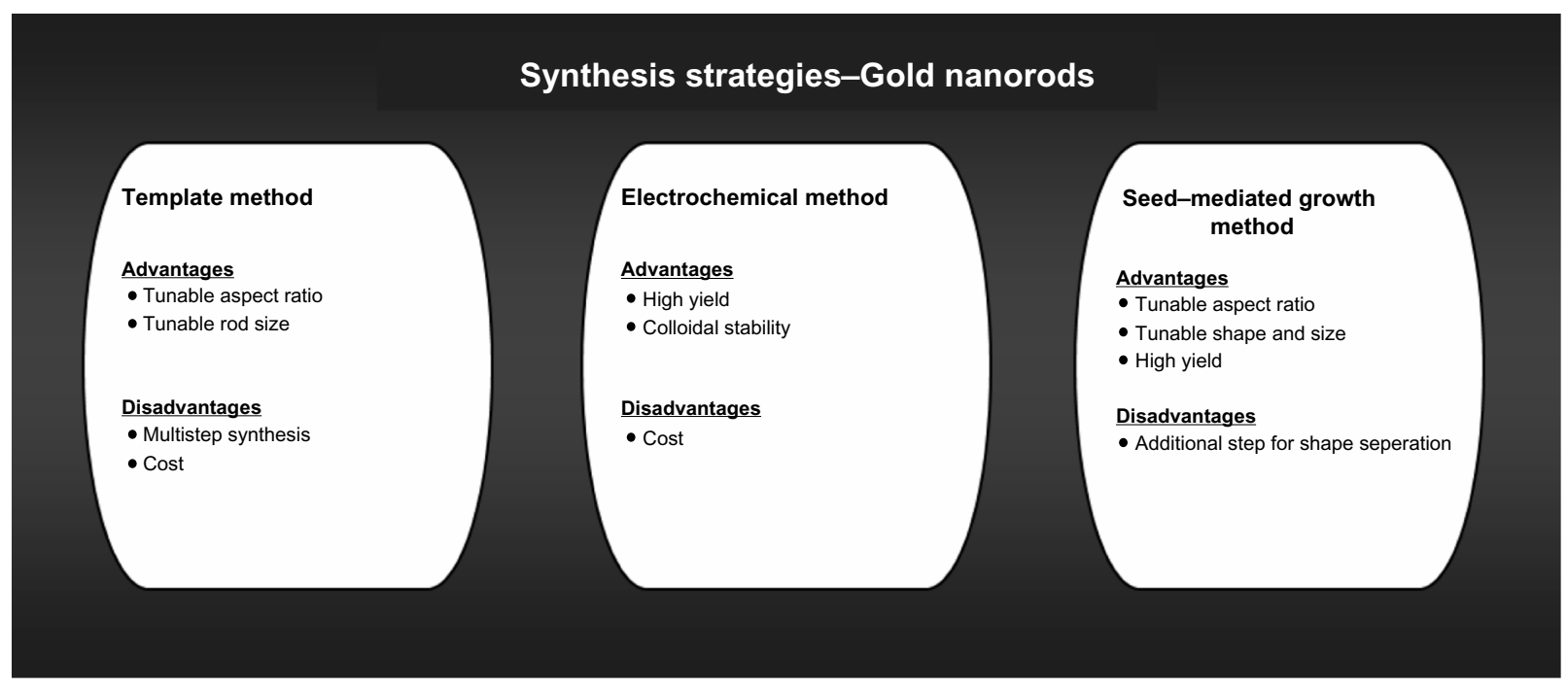

Figure 3 Methods for the synthesis of gold nanorods. 
ions and their release rates were found to affect the length of GNRs. ${ }^{48}$

\section{Seed-mediated growth method}

The seed-mediated growth method has been used for decades to synthesize monodispersed metal nanoparticles. Brown et al were the first to use the seed-mediated growth method for the synthesis of GNRs by reducing auric gold $\left(\mathrm{Au}^{3+}\right)$ with hydroxylamine. ${ }^{49}$ One of the major biocompatibility issues of the seed-mediated growth method is the formation of nanoparticles of other shapes along with nanorods.

Jana et al synthesized GNRs using $3.5 \mathrm{~nm}$ seed nanoparticles. ${ }^{50}$ The yield of this method was $4 \%$, but it was later improved by changing the $\mathrm{pH}$ of the growth solution from 2.8 to 5.6. The change in $\mathrm{pH}$ resulted in formation of GNRs with an aspect ratio between 18 and 20 and a yield of $90 \%{ }^{51} \mathrm{Hu}$ et al used various temperatures and capping agents for GNR synthesis. ${ }^{52}$ It appeared that a reduced temperature and the use of hexadecyltrimethylammonium bromide as capping agent led to nanorods with an aspect ratio between 1 and 6 and a yield in the order of $50 \%$. The study also suggested that stability of seeds, growth temperature, and concentration of surfactant influence monodispersity, yield, and aspect ratio.

The seed-mediated growth method does not only generate nanorods but also nanoparticles of various shapes. For this reason, separation of nanorods from other nanoparticles is critical. Methods such as size-selective precipitation, nanoporous filtration, and methods for extraction have successfully separated nanospheres of different sizes but are not very selective for nanorods due to their relatively large size. ${ }^{53,56}$ Wei et al demonstrated that size-exclusion chromatography can separate nanorods from spheres, but this method is only partly successful. ${ }^{54}$ Jana used phase-separation involving surfactant-assisted ordering. ${ }^{55}$ The method successfully separated single-sized nanorods from a mixture of differentlysized rods, spheres, and plates. More recently, Sharma et al demonstrated centrifugation as an efficient technique to separate nanorods from a mixture of nanorods and nanospheres. ${ }^{56}$ The technique is based on the fact that shape-dependent drag causes particles to have shape-dependent sedimentation behavior.

\section{Methods for the surface modification of GNRs}

GNRs synthesized using the above mentioned methods have dispersion and biocompatible flaws and therefore need further surface modification before use as hyperthermia agents. ${ }^{57}$ There are two main strategies for surface modification of GNRs: matrix entrapment and ligand exchange.

\section{Matrix entrapment}

Entrapment of GNRs in a matrix improves their dispersion and optical and chemical characteristics. Mitamura et al entrapped and dispersed GNRs in an alginate matrix using energy dispersive X-ray spectroscopy. Alginate entrapped GNRs were highly dispersed and maintained their optical character. ${ }^{58}$ Apart from alginate, poly(Nisopropylacrylamide) gel has also been used to disperse GNRs in a gel matrix. Gorelikov et $\mathrm{al}^{59}$ and Kumar et $\mathrm{al}^{60}$ dispersed GNRs in a poly(N-isopropylacrylamide) microgel using hybridization. The resulting hybrid gel was unique in that it was able to reversibly shrink with or without infrared radiation.

\section{Ligand exchange}

Surfactants used in the seed-mediated growth method for synthesis of GNRs are toxic. Ligand exchange has been the method of choice for removal of residual surfactants from GNRs. Gentili et al used a double phase transfer process for surface functionalization of GNRs. ${ }^{61}$ The process consisted of a simple one-step ligand exchange in a hydroalcoholic mixture with thiols and a phase transfer to entrap gold nanoparticles into polyethylene glycol-based polymeric nanoparticles. Thus, the obtained GNRs were lipophilic-free with a robust coating. Khanal et al synthesized GNRs stabilized by cetyltrimethylammonium bromide and subsequently exchanged the cetyltrimethylammonium bromide for a functional thiol using 4-mercaptophenol. ${ }^{62}$ The method resulted in formation of anisometric GNRs that self-assembled into ring-like superstructures.

\section{Carbon nanotubes}

Carbon nanotubes (CNTs) were first observed in 1952 by Radushkevich and Lukyanovich, but only in 1991 was a methodology for the synthesis of CNTs described by Iijima using C60 carbon molecules. ${ }^{63,64}$ CNTs are most commonly synthesized from allotropes of carbon in two different forms, such as single-walled carbon nanotubes (SWNTs) and multiwalled nanotubes (MWNTs). SWNTs consist of a single tube of graphene, and MWNTs consist of several concentric tubes of graphene (Figure 4). Both forms have unique physical and chemical properties that enable their application in anticancer hyperthermia therapy. CNTs generate heat upon infrared irradiation. Another salient feature of CNTs is the 

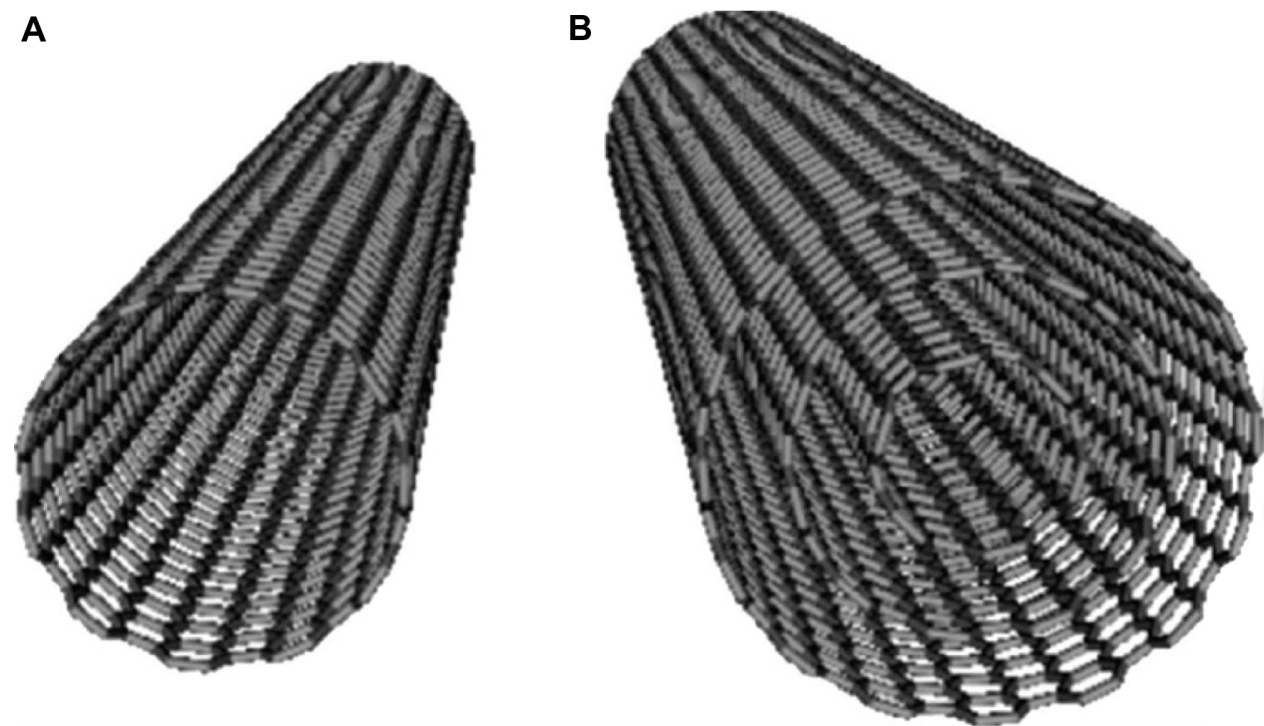

Figure 4 Structural arrangement of carbon in (A) single-walled nanotube and (B) multiwalled nanotube.

possibility to engineer their surface for conjugation with a wide variety of molecules. ${ }^{64}$

\section{Methods for synthesis of CNTs}

There are three major techniques for the synthesis of CNTs: arc discharge, laser ablation, and chemical vapor deposition (CVD). Arc discharge and laser ablation were the initial techniques used to synthesize CNTs. Both techniques require high temperatures (generally $>1,700^{\circ} \mathrm{C}$ ) and are now more or less obsolete, replaced by CVD which is carried out at comparatively low temperatures $\left(<800^{\circ} \mathrm{C}\right)$ and enables the synthesis of CNTs with controlled orientation, alignment, length, diameter, and density. ${ }^{65}$

\section{Arc discharge}

Arch discharge is a gas phase reaction process requiring high temperatures for synthesis of CNTs. The advantage of arc discharge is that CNTs with minimal imperfections and structural defects are generated. The process conditions are different for the synthesis of MWNTs and SWNTs.

\section{Synthesis of MWNTs}

Graphite electrodes are used for synthesis of MWNTs. The electrodes have a diameter of $8-12 \mathrm{~nm}$ and are water cooled. The reaction atmosphere consists of helium, hydrogen, or methane. The purity and yield of CNTs are found to vary with the gas atmosphere and pressure inside the reaction vessel. Wang et al used evaporation in methane under high pressure and high arc current to obtain thick nanotubes. ${ }^{66}$ Lowering the methane pressure and the current at the anode resulted in formation of thin and long MWNTs. Zhao et al used hydrogen gas instead of methane as reaction atmosphere and also obtained thin and long MWNTs. ${ }^{67}$

Another technique for arc discharge deposition is the use of pulsed current rather than direct current. Parkansky et al used a single-pulse arc to produce MWNTs with a diameter of $10 \mathrm{~nm}$ and a length of $3 \mu \mathrm{m} .{ }^{68}$ In addition to standard arc deposition, alternative methods have been used for synthesis of CNTs. Sornsuwit et a $\mathrm{l}^{69}$ and Montoro et a $\mathrm{l}^{70}$ used arc discharge in an aqueous vanadic acid solution to grow high quality SWNTs and MWNTs. Jung et al used arc discharge in the presence of liquid nitrogen to successfully grow MWNTs. ${ }^{71}$

\section{Synthesis of SWNTs}

Unlike MWNTs, SWNTs cannot be synthesized in the absence of a transition metal catalyst. The most commonly used method for the synthesis of SWNTs is based on an arc discharge system fitted with a composite anode. The composite anode consists of graphite and a combination of transition metals as catalyst. The catalyst plays an important role in increasing the yield of the process while high efficiency is ensured by a constant gap between electrodes.

Iijima et al were the first to synthesize SWNTs in $1993 .^{72}$ Later that year, Bethune et al utilized coevaporation of carbon and cobalt to generate SWNTs with a single atomic layer. ${ }^{73}$ Chen et al modified the electric arc technique for the synthesis of SWNTs by using a ferrium-hydrogen arc discharge. ${ }^{74}$ This new technique used hydrogen arc discharge with a carbon anode containing a $1 \%$ iron (Fe) catalyst in a mixed hydrogen-argon gas environment to produce highly 
crystalline SWNTs. The technique successfully generated SWNTs with a purity $>90 \%$. Fan et al further modified this technique to develop an economic process for the synthesis of SWNTs. ${ }^{75}$ The technique used argon as reaction atmosphere and direct current arc discharge with charcoal as carbon source and iron sulfide and cobalt oxide as catalyst. SWNTs thus formed were highly pure with a diameter of $1.2 \mathrm{~nm}$.

\section{CVD}

Arc discharge enables the generation of large quantities of CNTs with minimal imperfections but with low purity. CVD on the other hand produces CNTs with predefined properties and high purity.

CVD involves catalytic decomposition of hydrocarbon or carbon monoxide feedstock, with the aid of supported transition metal catalysts to produce CNTs. The synthesis is achieved by combining a carbon source with an energy source. Most commonly used energy and carbon sources are a plasma- and resistively-heated coil, methane, carbon monoxide, and acetylene. There are three main steps in the synthesis process. ${ }^{76}$ The first step is the cracking step, where the energy source is used to crack the gas phase molecule into atomic carbon. The second step is the diffusion step, during which cracked atomic carbon diffuses toward the substrate. The third step is the heating and coating step. During this step, diffused carbon is heated and coated with the metal catalyst while it binds to the catalyst. Excellent diameter control and growth rate can be achieved with CVD. The actual process for synthesis of CNTs consists of a catalyst preparation step that is followed by the actual synthesis of the nanotube. The catalyst preparation is performed by using either sputtering or chemical etching. The temperatures for the synthesis of nanotubes by CVD are usually within the $650^{\circ} \mathrm{C}-900^{\circ} \mathrm{C}$ range. Typical yields for CVD are approximately $30 \% .^{77}$

CVD has been used to create several structural forms of carbon, including SWNTs and MWNTs from well-crystallized graphite layers. CVD allows selective CNT growth in a variety of forms, such as powder and an aligned forest of CNTs. ${ }^{78,79}$

In the last decade, different CVD-based techniques have been developed for CNT synthesis, including plasmaenhanced CVD, thermal-chemical CVD, alcohol-catalytic CVD, vapor phase growth, aero gel-supported CVD, and laser-assisted CVD. ${ }^{80}$

\section{Hyperthermia with MNPs Hyperthermic therapy}

Hyperthermia using MNPs is often referred to as MHT. MHT involves injection of iron oxide nanoparticles inside the tumor and subsequent placement of the patient in an alternating magnetic field, which results in an increased intratumoral temperature, thermal ablation of tumor cells, and subsequent tumor shrinkage.

MHT is advantageous in two ways. First, MNPs accumulate in the tumor. Therefore, healthy tissue damage is limited. Second, MHT is noninvasive and capable of inducing hyperthermia in tumors at any location in the body. However, the efficiency of therapy is highly variable and often found to be dependent on particle properties, including size, magnetization, and Curie temperature. Curie temperature is an important parameter, indicating the maximum temperature of a magnetic particle. A good estimate of the Curie temperature allows an efficient temperature control and is thus critical to avoid overheating of tissue by MNPs. Besides particle properties, other parameters that play an important role in determining efficiency of MHT are intensity and frequency of the alternating magnetic field and the dissipation of heat from the tumor.

The effectiveness of MHT in glioma was first reported by Shinkai et al. ${ }^{81}$ In their first study, the group used an ex vivo rat model implanted with glioma cell pallets and magnetic cationic liposomes. Three doses of alternating magnetic field for 60 minutes each, at intervals of 12 hours were applied to the rats. The treatment was reported to completely inhibit tumor development for up to 90 days. ${ }^{81}$ In the second study, an in vivo rat model was used to examine the effect of hyperthermia in glioma tumors. ${ }^{82}$ Magnetite cationic liposomes were administered to rats, and histological analysis revealed that the rats that were exposed to the magnetic field showed a homogeneous distribution of magnetite cationic liposomes, which also coincided with the necrotic regions. In the third study, an in vivo model of rat with glioma tumors was used to study antitumor immunity of rats by hyperthermia therapy. ${ }^{83}$ During the primary treatment, three doses of 30 minutes each were applied at 24-hour intervals. Tumor tissue was completely eliminated in two-thirds of the rats. These rats were rechallenged with glioma cells 3 months later. Transient growth was observed in the initial 2 weeks, but the tumors disappeared in 4 weeks. The explanation for this phenomenon was promotion of anti-tumor response by activation of heat shock proteins (see below).

In the last two decades, other studies have also demonstrated the effectiveness of MHT, on its own as well as in combination with other therapies. Ito et al observed that hyperthermia promotes an anti-tumor immune response by activation of heat shock proteins. ${ }^{84}$ In a later study, it was suggested that hyperthermia in combination with gene therapy is an effective strategy for the treatment of GBM. ${ }^{85}$ Le et al demonstrated increased effectiveness of 
magnetite cationic liposomes in the destruction of GBM tissue by conjugating magnetic cationic liposomes to a specific antibody against GBM. ${ }^{86}$ Table 2 shows a comprehensive list of in vivo studies that evaluated SPIONs for GBM treatment.

Latest clinical trials in Europe suggest that the application of magnetic hyperthermia may become clinically effective soon. MagForce Nanotechnologies (Berlin, Germany) has developed a MHT system called "NanoTherm ${ }^{\circledR}$." The system is based on aminosilane-coated SPIONs and the application of an alternating magnetic field. This MHT system has received approval in Europe to use iron oxide MNPs for GBM treatment. ${ }^{87}$

\section{Hyperthermia as enhancer of drug delivery}

The term "hyperthermia" has thus far been confined to the use of heat for therapy. However, hyperthermia has also been utilized as a novel mechanism to improve drug delivery to tumors. ${ }^{88}$ The use of magnetic field to control drug release from polymeric matrices containing iron oxide was first reported nearly 30 years ago ${ }^{88,89}$ The MNP design for drug delivery is unique and generally consists of an iron oxide core and a polymer shell. The polymer shell is heat sensitive, and upon heat transferred from the iron oxide core, it contracts to release the encapsulated drug. MNP systems based on this concept are able to deliver drugs in a controlled manner. Control is possible because of the sensitivity of the MNP shell to a magnetic field, which is a function of frequency and strength of alternating magnetic field. ${ }^{90}$

Hyperthermia-mediated release of various drugs was first demonstrated using temperature-sensitive poly(N-isopropylacrylamide) hydrogels incorporating SPIONs. ${ }^{91}$ Hoare et al demonstrated on-demand release of sodium fluorescein using nanocomposite membranes of thermosensitive poly( $\mathrm{N}$-isopropylacrylamide)-based nanogels and magnetite nanoparticles ${ }^{92}$ (Figure 5). This study opened avenues for the development of therapeutic systems such as magnetic micro- and nanopumps, magnetic field-controlled drug delivery devices, and magnetic switches.

A more recent design of a magnetic drug delivery platform is magnetic composite nanoparticles consisting of multiple metals. Behrens et al demonstrated the potential of ferromagnetic cobalt nanoparticles in modulating the permeability of polyelectrolyte microcapsules. ${ }^{93}$ In this study, ferromagnetic gold-coated cobalt nanoparticles were embedded inside polymeric walls using the layer-by-layer self-assembly technique. The polymer capsules consisted of eleven layers, with one layer of ferromagnetic goldcoated cobalt nanoparticles and ten layers of polyelectrolyte bilayers. The polymer capsule design was found to be ideal for the magnetic control of the permeability of the composite nanoparticle.

Another interesting type of MNPs for drug delivery is iron-core and silica-shell nanoparticles. This nanoparticle design is unique because it protects biomolecules that are encapsulated in the shell from the environment. The core-shell nanoparticles resemble extracellular vesicles. Extracellular vesicles are small granules that are produced by cells in our body to deliver biological materials to recipient cells. ${ }^{94}$

More recently, implantable microchips have been developed on the basis of MNPs, such as a novel drug-delivery chip for magnetically-controlled release of anti-epileptic drugs $^{95,96}$ (Figure 6). The chip was made of an electricallyconductive flexible polyethylene terephthalate substrate that contained drug-loaded magnetic SPION-core-silica-shell nanoparticles.

\section{Hyperthermia with GNRs Hyperthermic therapy}

Gold nanoparticles possess unique optical properties of which surface plasmon resonance is the most important.

Table 2 In vivo animal model studies to evaluate MHT using SPION for thermal ablation of GBM

\begin{tabular}{|c|c|c|c|c|c|c|}
\hline Study & $\begin{array}{l}\text { Tumor } \\
\text { cell line }\end{array}$ & Animal & Sex & $\begin{array}{l}\text { Age } \\
\text { (weeks) }\end{array}$ & Injection site & $\begin{array}{l}\text { Minimum } \\
\text { inoculation (cells) }\end{array}$ \\
\hline Jordan et al ${ }^{19}$ & RG-2 & Fisher rat F-344 & Male & - & Thalamus region & $1 \times 10^{6}$ \\
\hline Shinkai et $\mathrm{al}^{81}$ & T9 & Fisher rat F-344 & Female & $6-7$ & Subcutaneous (left femoral region) & $\mathrm{I} \times 10^{6}$ \\
\hline Yanase et $a^{82}$ & T9 & Fisher rat F-344 & Female & $7-8$ & Subcutaneous (left femoral region) & $1 \times 10^{6}$ \\
\hline Yanase et $\mathrm{al}^{83}$ & T9 & Fisher rat F-344 & Female & $6-7$ & Subcutaneous (left femoral region) & $\mathrm{I} \times 10^{6}$ \\
\hline Ito et $\mathrm{al}^{84}$ & U-25I-SP & Athymic nude mice & Female & 4 & $\begin{array}{l}\text { Subcutaneous (left and right femoral } \\
\text { regions) }\end{array}$ & $1 \times 10^{6}$ \\
\hline Ito et $\mathrm{al}^{85}$ & T9 & Fisher rat F-344 & Female & 6 & Subcutaneous space & $1 \times 10^{6}$ \\
\hline Le et $\mathrm{al}^{86}$ & U-25I-SP & $\mathrm{KSN}$ - nu/nu nude mice & Female & 4 & Subcutaneous (femoral region) & $1 \times 10^{6}$ \\
\hline
\end{tabular}

Abbreviations: GBM, glioblastoma multiforme; MHT, magnetic hyperthermia therapy; SPION, superparamagnetic iron oxide nanoparticles. 


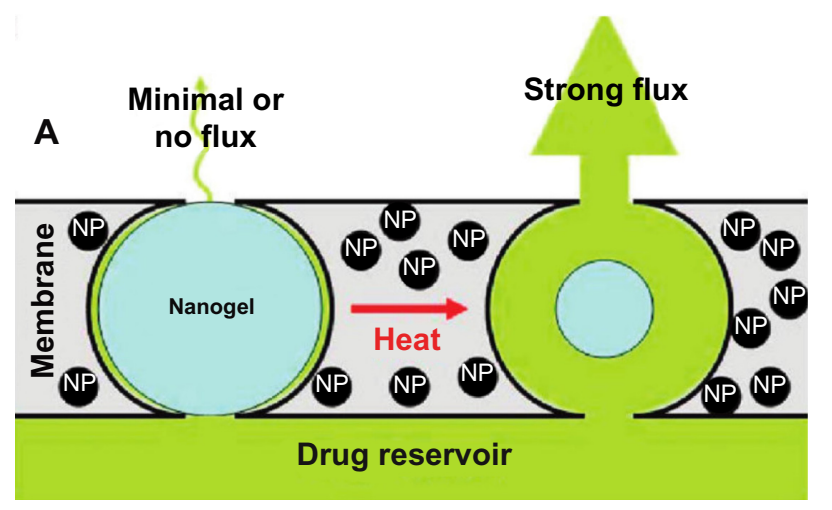

B

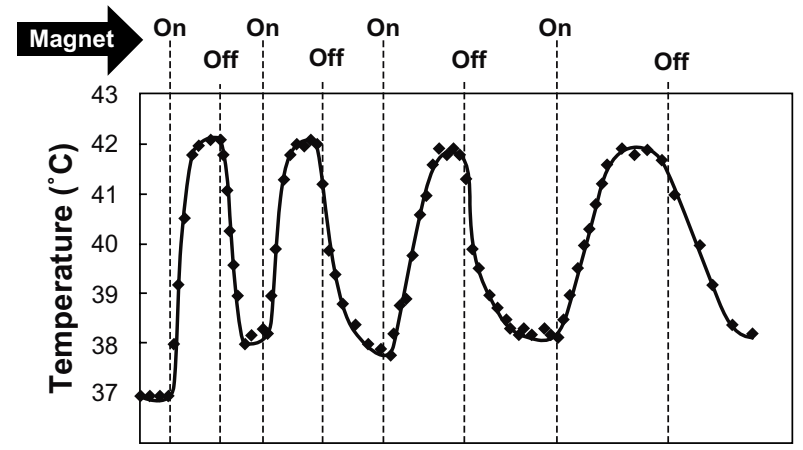

Figure 5 Stimulus-responsive membrane triggered in vitro (A) and magnetic triggering and differential flux of sodium fluorescein out of membrane-capped devices as a function of timeover successive on/off cycles of external magnetic field (B). Reprinted with permission from Hoare T, Santamaria J, Goya GF, et al. A magnetically triggered composite membrane for on-demand drug delivery. Nano Lett. 2009;9( I0): 3651-3657. Copyright (C 2009. American Chemical Society. ${ }^{92}$

Abbreviation: NP, nanoparticle.

Surface plasmon resonance is the collective oscillation of electrons in a solid or liquid state stimulated by incident light. In the case of gold nanoparticles, absorption of infrared light induces surface plasmon resonance that is converted into heat. GNRs have the greatest potential for biomedical applications because of their high light absorption efficiency per unit volume. GNRs exhibit two distinct surface plasmon oscillations: a strong band in the near infrared region, corresponding to electron oscillation along the long axis (longitudinal band) and a weak band in the visible region (transverse band). Only the longitudinal band is sensitive to size changes and can be shifted from the visible to the near infrared region by adjusting the aspect ratio (length/width) during synthesis. ${ }^{97}$

GNRs have attracted great interest for hyperthermic therapy due to superior biocompatibility. The effectiveness of GNRs in hyperthermic anti-tumor therapy has been demonstrated. ${ }^{97}$ GNRs have been conjugated with molecules that carry sequences that can bind to cancer biomarkers. These GNRs specifically target and destroy tumors. Oral cancers are known to overexpress folate receptors, and therefore many studies utilized GNR conjugated with folic acid to target oral cancer cells. The study successfully ablated oral cancer cells in a targeted manner. ${ }^{98}$ Choi et al used PEGylated GNRs conjugated with an Arg-Gly-Asp sequence to specifically bind to $\alpha v \beta 3$ integrins expressed on GBM cells. ${ }^{99}$ The study demonstrated that (Arg-Gly-Asp)-GNRs are able to circulate for prolonged periods of time and bind to GBM cell surface, thus targeting GNRs to the GBM tumor. Fernandez et al developed an optical hyperthermia method for treatment of GBM by irradiation of GNRs by laser light and was successful in ablating GBM cells in vitro. ${ }^{100}$ Oli et al used folate-conjugated GNRs to specifically target GBM cells. ${ }^{101}$ The study showed that folate-conjugated GNRs can successfully target and kill GBM cells upon excitation with a near infrared laser.

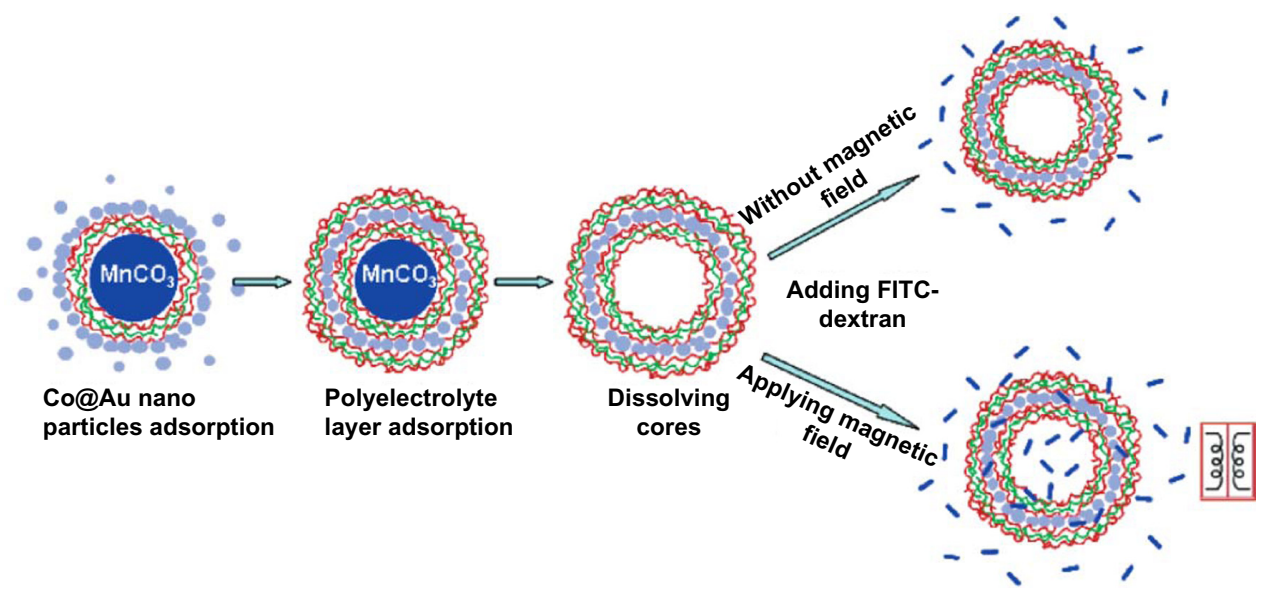

Figure 6 Layer-by-layer self-assembly and permeability test for microcapsules embedded with ferromagnetic gold-coated cobalt nanoparticles under an oscillating magnetic field. Reprinted with permission from Zonghuan L, Malcolm PD, Zhanhu G, et al. Magnestic switch of permeability for polyelectrolyte microcapsules embedded with nanoparticles. Langmuir. 2005;21:2042-2050. Copyright @ 2005. American Chemical Society. ${ }^{109}$

Abbreviations: Co@Au, ferromagnetic gold-coated cobalt; FITC, fluorescein isothiocyanate; $\mathrm{MnCO}_{3}$, manganese carbonate. 


\section{Hyperthermia as enhancer of drug delivery}

GNRs have also been studied as enhancers of drug delivery. GNRs offer tunable and localized surface plasmon resonance, which makes them highly localized heat sources when irradiated with a laser. The heat generated by GNRs is used for hyperthermic cancer therapy and/or to trigger the release of a drug.

Although drug delivery using GNRs is a new field, there are two major studies that investigated the use of GNRs to deliver doxorubicin to GBM. Agarwal et al were the first to study remotely triggered release of doxorubicin in GBM tumors using thermosensitive liposomes and GNRs. ${ }^{102}$ PEGylated GNRs triggered release of doxorubicin from thermosensitive liposomes in a mouse tumor model of human GBM when irradiated with near infrared light. The stimulation resulted in significantly increased efficacy when compared to nontriggered or nonthermosensitive PEGylated liposomes. More recently, Xiao et al studied GNRs conjugated with doxorubicin and cyclo(Arg-Gly-Asp-D-Phe-Cys) peptide for drug delivery in GBM. ${ }^{103}$ Doxorubicin was covalently conjugated to PEGylated GNRs via a hydrazone bond. Flow cytometric analysis revealed that GNRs conjugated with doxorubicin and cyclo(Arg-Gly-Asp-D-Phe-Cys) peptide exhibited a higher cellular uptake and cytotoxicity than nontargeted GNRs conjugated with doxorubicin in human GBM cells.

Zhang et al evaluated the potential of mesoporous silicacoated GNRs for cancer theranostics in a proof of concept study in human alveolar adenocarcinoma cells. ${ }^{104}$ The core of GNRs functioned both as an agent that allowed noninvasive imaging as well as a hyperthermic agent while the outer mesoporous silica shell encapsulated a high drug load, thus posing itself as an effective drug carrier (Figure 7).

\section{Hyperthermia with CNTs}

Hyperthermia using CNTs is a new field compared to MNPand GNR-mediated hyperthermia. CNTs exhibit unique physical and chemical properties that hold promise for drug delivery and cancer therapy. ${ }^{105}$ The mechanisms of selective tumor targeting with CNTs are currently being explored due to their impressive ability to convert near infrared light into heat. This intrinsic property of CNTs opens new avenues for the development of novel nanostructures for cancer phototherapy. ${ }^{105}$

Markovic et al used CNTs and graphene nanoparticles for hyperthermic ablation of human glioma cells in vitro. ${ }^{106}$ The study showed that graphene nanoparticles triggered cell death by inducing oxidative stress, and CNTs triggered cell
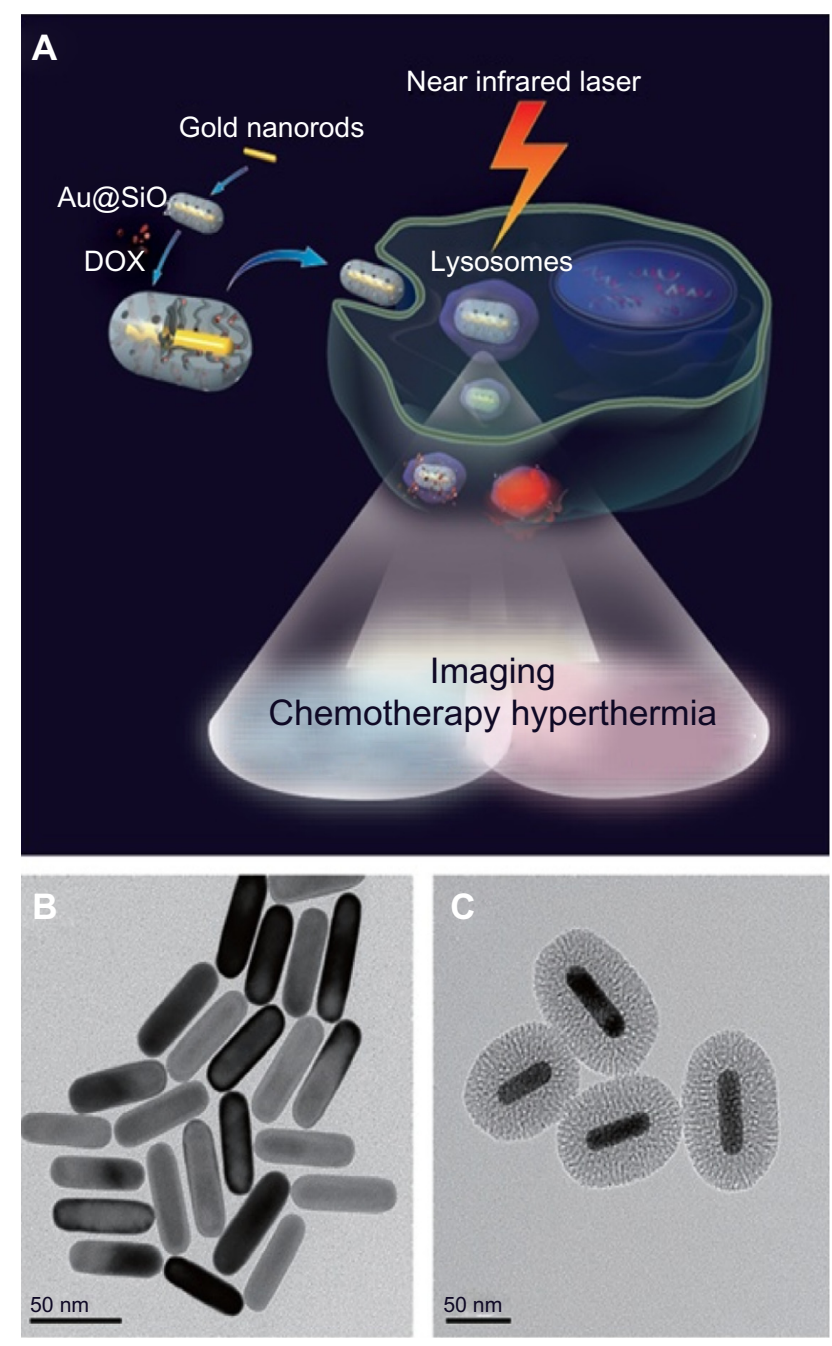

Figure 7 Mechanism of action of mesoporous silica-coated gold nanorods (A), gold nanorods without coating (B), and mesoporous silica-coated GNRs (C).

Notes: The core of GNRs functioned both as an agent that allowed noninvasive imaging as well as a hyperthermic agent while the outer mesoporous silica shell encapsulated a high drug load, thus posing itself as an effective drug carrier. Reproduced from Zhang Z, Wang L, Wang J, et al. Mesoporous silica-coated gold nanorods as a light-mediated multifunctional theranostic platform for cancer treatment. Adv Mater. 2012;24(I I):1418-1423. ${ }^{104}$ Copyright (C) 2012 WILEY-VCH Verlag GmbH \& Co. KGaA, Weinheim.

Abbreviations: Au@SiO2, silica-coated gold nanorods; DOX, doxorubicin; GNRs, gold nanorods.

death via mitochondrial membrane depolarization. Wang et al incubated GBM cells with anti-CD133 monoclonal antibody-conjugated SWNTs, ${ }^{107}$ and irradiation with near infrared laser light resulted in targeted ablation of GBM cells while the viability of control cells remained unaffected. In a second study, Wang et al generated anti-GD2conjugated CNTs to target GD2 receptors present on the surface of neuroblastoma cells. ${ }^{108}$ Neuroblastoma cells were pretreated with anti-GD2-conjugated CNTs and were then irradiated with a near infrared laser. Postexposure analysis revealed necrosis among GD2-positive cells, whereas GD2negative (control) cells remained unaffected. These studies suggest that SWNTs and MWNTs possess unique optical 
properties that have potential to develop novel therapies for the treatment of GBM.

\section{Conclusion}

GBM is an aggressive tumor type with very low survival rates. Many factors attribute to the low survival rates; some are inherent while others are treatment dependent. Conventional therapies lack specificity for cancer cells and therefore lead to side effects. Conventional therapies in combination with alternative or adjuvant therapies provide a better treatment strategy but still lack the efficacy and potential that is needed for effective treatment of GBM.

Conventional hyperthermia with external devices has been used for a long time but lacks accurate temperature control, leading to overheating and damage of healthy tissue or dissipation of heat from the tissue. Hyperthermia using nanoparticles is a novel concept that enables controlled heating of tumor tissue. Nanoparticle-based hyperthermia can have direct therapeutic effects and enhance drug delivery in a single therapy, making it a therapy with two advantages for cancer treatment.

MNPs, GNRs, and CNTs are the most promising nanoparticles for hyperthermic therapy in GBM. Among MNPs, SPIONs are the nanoparticles of choice for treatment of GBM. The salient features of SPIONs are:

- ease of synthesis;

- superior biocompatibility; and

- relatively low cost.

Cationic liposomes and aminosilane-coated SPIONs have been found to be effective in ablating GBM in the presence of an alternating magnetic field. MagForce Nanotechnolgies has commercialized MHT for the treatment of GBM after successful Phase I, II, and III trials.

In addition to high treatment efficacy, many studies ${ }^{81,82}$ have also confirmed an antitumor immune response after hyperthermia, based on elevated expression of heat shock proteins, which is an added advantage.

Core-shell SPIONs, when incorporated with drugs and stimulated with alternating magnetic field, are capable of drug delivery in a controlled manner. Layer-by-layer selfassembly is the preferred method for synthesis of core-shell SPIONs. Drug delivery and hyperthermia using SPIONs is promising yet challenging. Advantages of SPION-based hyperthermia are:

- ability to cross the blood-brain barrier;

- delivery through multiple routes;

- minimal or no side effects;
- noninvasive procedure; and

- antitumoral immunity.

Some of the challenges on the other hand are moderate to low absorption rates, monitoring temperature distribution, self-regulation of heating, and precise control of intratumoral temperature.

Gold nanoparticles exhibit exceptional physical and optical properties including surface plasmon resonance. These properties enabled the development of novel photothermal therapies for the treatment of GBM. GNRs encompass better properties than gold nanospheres including superior biocompatibility and higher light absorption per unit volume.

GNRs are prepared by either wet or dry chemistry. Wet chemistry is the preferred mode due to the simple and inexpensive nature of synthesis. Most investigated wet chemistrybased methods for GNR synthesis are:

- template;

- electrochemical; and

- seed-mediated growth.

When GNRs are intravenously injected in in vivo models of GBM and irradiated with near infrared laser light, they cause significant thermal ablation of tumor cells via necrosis and/or apoptosis. This procedure is successful in reducing tumor volume but often leads to nonspecific heating of surrounding healthy tissue. Conjugation of GNRs with cell surface targeting antibodies or aptamers can overcome these nonspecific heating effects. Studies have successfully used $\alpha v \beta 3$ integrins and folate receptors to target GNRs to GBM cells.

Core-shell GNRs are versatile nanocarriers for drug delivery. Studies have successfully delivered doxorubicin as model drug to GBM cells using targeted as well as nontargeted approaches.

In summary, core-shell versions of GNR are capable of:

- controlled drug delivery;

- hyperthermia; and

- combinational therapy.

Development of multifunctional systems based on coreshell MNPs and GNRs with individual functions acting in a coordinated way is critical to optimize therapeutic efficacy and safety of therapeutic regimes, and could provide more opportunities for on-demand therapy and pave the road toward personalized medicine.

CNTs and graphene nanoparticles exhibit an impressive ability to convert near infrared light into heat. This intrinsic property of CNTs is utilized to develop hyperthermic therapy 
for GBM treatment. The studies suggest that CNTs and graphene nanoparticles can effectively ablate glioma cells in a targeted as well as a nontargeted manner. Although CNTs are successful in cancer phototherapy, further studies are needed to elucidate all mechanisms involved in CNTmediated anticancer therapy.

Among MNPs, GNRs, and CNTs, SPIONs are promising in the development of MHT, GNRs are promising in the development of photodynamic therapy, and CNTs have potential in the development of photothermal therapy for the treatment of GBM.

\section{Disclosure}

The authors report no conflicts of interest in this work.

\section{References}

1. Brandes AA, Tosoni A, Franceschi E, Reni M, Gatta G, Vecht C. Glioblastoma in adults. Crit Rev Oncol Hematol. 2008;67(2):139-152.

2. Wen PY, Kesari S. Malignant gliomas in adults. $N$ Engl $J$ Med. 2008;359(5):492-507.

3. Iacob G, Dinca EB. Current data and strategy in glioblastoma multiforme. J Med Life. 2009;2(4):386-393.

4. Piroth MD, Gagel B, Pinkawa M, Stanzel S, Asadpour B, Eble MJ. Postoperative radiotherapy of glioblastoma multiforme: analysis and critical assessment of different treatment strategies and predictive factors. Strahlenther Onkol. 2007;183(12):695-702.

5. Stupp R, Mason WP, van den Bent MJ, et al; European Organisation for Research and Treatment of Cancer Brain Tumor and Radiotherapy Groups; National Cancer Institute of Canada Clinical Trials Group. Radiotherapy plus concomitant and adjuvant temozolomide for glioblastoma. New Eng J Med. 2005;352(10):987-996.

6. Moustakas A, Kreisl TN. New treatment options in the management of glioblastoma multiforme: a focus on bevacizumab. Onco Targets Ther. 2010;3:27-38.

7. Stupp R, Hegi ME, Mason WP, et al; European Organisation for Research and Treatment of Cancer Brain Tumour and Radiation Oncology Groups; National Cancer Institute of Canada Clinical Trials Group. Effects of radiotherapy with concomitant and adjuvant temozolomide versus radiotherapy alone on survival in glioblastoma in a randomised phase III study: 5-year analysis of the EORTC-NCIC trial. Lancet Oncol. 2009;10(5):459-466.

8. Hildebrandt B, Wust $\mathrm{P}$, Ahlers $\mathrm{O}$, et al. The cellular and molecular basis of hyperthermia. Crit Rev Oncol Hematol. 2002;43(1):33-56.

9. Wust P, Hildebrandt B, Sreenivasa G, et al. Hyperthermia in combined treatment of cancer. Lancet Oncol. 2002;3(8):487-497.

10. Jordan A. Thermotherapy and nanomedicine: between vision and reality. In: Baronzio GF, Hager ED, editors. Hyperthermia in Cancer Treatment: A Primer. 3rd ed. New York, NY: Springer; 2006:60-63.

11. Elliott DG, Haskins GM, Rand RW, Snow HD; inventors. Induction heating method for use in causing necrosis of neoplasm. United States Patent US4545368 A. October 8, 1985.

12. Gilchrist RK, Medal R, Shorey WD, Hanselman RC, Parrott JC, Taylor CB. Selective inductive heating of lymph nodes. Ann Surg. 1957;146(4):596-606.

13. Ito A, Shinkai M, Honda H, Kobayashi T. Medical application of functionalized magnetic nanoparticles. J Biosci Bioeng. 2005;100(1):1-11.

14. Mornet S, Vasseur S, Grasset F, et al. Magnetic nanoparticle design for medical applications. Prog Solid State Chem. 2006;34(2-4):237-247.

15. Faraji M, Yamini Y, Rezaee M. Magnetic nanoparticles: synthesis, stabilization, functionalization, characterization, and applications. J Iran Chem Soc. 2010;7(1):1-37.
16. Petri-Fink A, Hofmann H. Superparamagnetic iron oxide nanoparticles (SPIONs): from synthesis to in vivo studies - a summary of the synthesis, characterization, in vitro, and in vivo investigations of SPIONs with particular focus on surface and colloidal properties. IEEE Trans Nanobioscience. 2007;6(4):289-297.

17. Editors of Encyclopaedia Britannica. Curie point [webpage on the Internet]. Encyclopaedia Britannica. Available from: http://www.britannica.com/ EBchecked/topic/146902/Curie-point. Accessed October 14, 2013.

18. Martirosyan KS. Thermosensitive magnetic nanoparticles for selfcontrolled hyperthermia cancer treatment. J Nanomed Nanotechnol. 2012;3(6):1-2.

19. Jordan A, Scholz R, Maier-Hauff K, et al. The effect of thermotherapy using magnetic nanoparticles on rat malignant glioma. J Neurooncol. 2006;78(1):7-14.

20. Lu AH, Salabas EL, Schüth F. Magnetic nanoparticles: synthesis, protection, functionalization, and application. Angew Chem Int Ed Engl. 2007;46(8):1222-1244.

21. Wu W, He Q, Jiang C. Magnetic iron oxide nanoparticles: synthesis and surface functionalization strategies. Nanoscale Res Lett. 2008;3(11): 397-415.

22. Suh SK, Yuet K, Hwang DK, Bong KW, Doyle PS, Hatton TA. Synthesis of nonspherical superparamagnetic particles: in situ coprecipitation of magnetic nanoparticles in microgels prepared by stop-flow lithography. J Am Chem Soc. 2012;134(17):7337-7343.

23. Perez De Berti IO, Cagnoli MV, Pecchi G, et al. Alternative low-cost approach to the synthesis of magnetic iron oxide nanoparticles by thermal decomposition of organic precursors. Nanotechnology. 2013; 24(17):175601.

24. Sun S, Zeng H. Size-controlled synthesis of magnetite nanoparticles. J Am Chem Soc. 2002;124(28):8204-8205.

25. Hyeon T, Lee SS, Park J, Chung Y, Na HB. Synthesis of highly crystalline and monodisperse maghemite nanocrystallites without a size-selection process. J Am Chem Soc. 2001;123(51):12798-12801.

26. Park J, An K, Hwang Y, et al. Ultra-large-scale syntheses of monodisperse nanocrystals. Nat Mater. 2004;3(12):891-895.

27. Inouye K, Endo R, Otsuka Y, Miyashiro K, Kaneko K, Ishikawa T. Oxygenation of ferrous ions in reversed micelle and reversed microemulsion. J Phys Chem. 1982;86(8):1465-1469.

28. Lee Y, Lee J, Bae CJ, et al. Large-scale synthesis of uniform and crystalline magnetite nanoparticles using reverse micelles as nanoreactors under reflux conditions. Adv Functional Mat. 2005;15(3):503-509.

29. Peng DL, Sumiyama K, Hihara T, Yamamuro S, Konno TJ. Magnetic properties of monodispersed Co/CoO clusters. Phys Rev B. 2000;61(4): 3103-3109.

30. Bönnemann H, Brijoux W, Brinkmann R, et al. A size-selective synthesis of air stable colloidal magnetic cobalt nanoparticles. Inorganica Chimica Acta. 2003;350:617-624.

31. Massart R. Preparation of aqueous magnetic liquids in alkaline and acidic media. Magn IEEE Trans. 1981;17(2):1247-1248.

32. Shen L, Laibinis PE, Hatton TA. Bilayer surfactant stabilized magnetic fluids: synthesis and interactions at interfaces. Langmuir. 1999; 15(2):447-453.

33. Sousa MH, Tourinho FA. New electric double-layered magnetic fluids based on copper, nickel, and zinc ferrite nanostructures. JPhys Chem B. 2001;105(6):1168-1175.

34. Wan M, Li J. Synthesis and electrical-magnetic properties of polyaniline composites. J Polym Sci A. 2003;36(15):2799-2805.

35. Butterworth MD, Bell SA, Armes SP, Simpson AW. Synthesis and characterization of polypyrrole-magnetite-silica particles. J Colloid Interf Sci. 1996;183(1):91-99.

36. Asti G, Solzi M, Ghidini M. Influence of domain walls on the singular point detection of energy losses in hard magnetic materials. J Magn Magn Mater. 2005;290-291(Pt 1):533-535.

37. Barratt G. Colloidal drug carriers: achievements and perspectives. Cell Mol Life Sci. 2003;60(1):21-37.

38. Cho SJ, Idrobo JC, Olamit J, Liu K, Browning ND, Kauzlarich SM. Growth mechanisms and oxidation-resistance of gold-coated iron nanoparticles. Chem Mater. 2005;17(12):3181-3186. 
39. Caruntu D, Cushing BL, Caruntu G, O'Connor CJ. Attachment of gold nanograins onto colloidal magnetite nanocrystals. Chem Mater. 2005;17(13):3398-3402.

40. Ban Z, Barnakov YA, Li F, Golub VO, O'Connor CJ. The synthesis of core-shelliron@gold nanoparticles and their characterization.J Mater Chem. 2005;15:4660-4662.

41. Liu Q, Xu Z, Finch JA, Egerton R. A novel two-step silica-coating process for engineering magnetic nanocomposites. Chem Mater. 1998;10(12):3936-3940.

42. Zhang J, Post M, Veres T, et al. Laser-assisted synthesis of superparamagnetic Fe@Au core-shell nanoparticles. J Phys Chem B. 2006;110(14):7122-7128.

43. Chen H, Shao L, Li Q, Wang J. Gold nanorods and their plasmonic properties. Chem Soc Rev. 2013;42:2679-2724.

44. Young JK, Figueroa ER, Drezek RA. Tunable nanostructures as photothermal theranostic agents. Ann Biomed Eng. 2012;40(2):438-459.

45. Vigderman L, Khanal BP, Zubarev R. Functional gold nanorods: synthesis, self-assembly, and sensing applications. Adv Mater. 2012;24(36):4811-4841.

46. Genzel L, Martin TP, Kreibig U. Dielectric function and plasma resonances of small metal particles. Z Physik B. 1975;21(4): 339-346.

47. Nikoobakht B, Wang ZL, El-Sayed MA. Self-Assembly of gold nanorods. J Phys Chem B. 2000;104(36):8635-8640.

48. Kim JY, Ah CS, Jang DJ. Controlled aspect ratios of gold nanorods in reduction-limited conditions. J Nanomater. 2011;405853:1-7.

49. Brown KR, Walter DG, Natan MJ. Seeding of colloidal Au nanoparticle solutions. 2. Improved control of particle size and shape. Chem Mater. 2000;12(2):306-313.

50. Jana NR, Gearheart L, Murphy CJ. Seed mediated growth approach for shape-controlled synthesis of spheroidal and rod-like gold nanoparticles using a surfactant template. Adv Mater. 2001;13(18):1389-1393.

51. Jana NR, Gearheart L, Murphy CJ. Wet chemical synthesis of high aspect ratio gold nanorods. $J$ Phys Chem B. 2001;105(19):4065-4067.

52. Hu M, Hillyard P, Hartland GV, Kosel T, Perez-Juste J, Mulvaney P. Determination of the elastic constants of gold nanorods produced by seed-mediated growth. Nano Lett. 2004;4(12):2493-2497.

53. Wu W, Huang J, Wu L, et al. Two-step size- and shape-separation of biosynthesized gold nanoparticles. Sep Purif Technol. 2013;106: 117-122.

54. Wei GT, Liu FK, Wang CRC. Shape separation of nanometer gold particles by size exclusion chromatography. Anal Chem. 1999;71(11): 2085-2091.

55. Jana NR. Nanorod shape separation using surfactant assisted selfassembly. Chem Commun. 2003;15:1950-1951.

56. Sharma V, Park K, Srinivasarao M. Shape separation of gold nanorods using centrifugation. Proc Natl Acad Sci U S A. 2009;106(13): 4981-4985.

57. Mitamura K, Imae T. Functionalization of gold nanorods toward their applications. Plasmonics. 2009;4:23-30.

58. Mitamura K, Imae T, Saito N, Takai O. Fabrication and structure of alginate gel incorporating gold nanorods. J Phys Chem C. 2008;112(2): 416-422.

59. Gorelikov I, Field LM, Kumacheva E. Hybrid microgels photoresponsive in the near-infrared spectral range. J Am Chem Soc. 2004;126(49): $15938-15939$

60. Kumar VRR, Samal AK, Sreeprasad TS, Pradeep T. Gold nanorods grown on microgels leading to hexagonal nanostructures. Langmuir. 2007;23(17):8667-8669.

61. Gentili D, Ori G, Franchini MC. Double phase transfer of gold nanorods for surface functionalization and entrapment into PEG-based nanocarriers. Chem Commun. 2009;39:5874-5876.

62. Khanal BP, Zubarev ER. Rings of nanorods. Angew Chem Int Edit. 2007;46(13):2195-2198.

63. Radushkevich LV, Lukyanovich VM. About structure of carbon created at thermal decomposition of carbon monoxide on iron contact. $J$ Phys Chem. 1952;26:88-95.
64. Iijima S. Helical microtubules of graphitic carbon. Nature. 1991;354: $56-58$.

65. Kumar M, Ando Y. Chemical vapor deposition of carbon nanotubes: a review on growth mechanism and mass production. $J$ Nanosci Nanotechnol. 2010;10(6):3739-3758.

66. Wang M, Zhao X, Ohkohchi M, Ando Y. Carbon nanotubes grown on the surface of cathode deposit by arc discharge. Fullerene Sci Technol. 1996;4(5):1027-1039.

67. Zhao XL, Wang M, Ohkohchi M, Ando Y. Morphology of carbon nanotubes prepared by carbon arc. Jpn J Appl Phys. 1996;35(Pt 1): 4451-4456.

68. Parkansky N, Boxman RL, Alterkop B, Zontag I, Lereah Y, Barkay Z. Single-pulse arc production of carbon nanotubes in ambient air. J Phys D Appl Phys. 2004;37(19):2715-2719.

69. Sornsuwit N, Maaithong W. Study of multi-walled carbon nanotubes synthesis using liquid nitrogen and the purification. Poster presented at: Asian Symposium for Precision Engineering and Nanotechnology; November 6-9, 2007; Gwangju, South Korea.

70. Montoro LA, Lofrano RCZ, Rosolen JM. Synthesis of single-walled and multi-walled carbon nanotubes by arc-water method. Carbon. 2005;43:200-203.

71. Jung SH, Kim MR, Jeong SH, et al. High-yield synthesis of multi-walled carbon nanotubes by arc discharge in liquid nitrogen. Appl Phys A. 2003;76(2):285-286

72. Iijima S, Ichihashi T. Single-shell carbon nanotubes of 1-nm diameter. Nature. 1993;363:603-605.

73. Bethune DS, Kiang CH, De Vries MS, et al. Cobalt-catalysed growth of carbon nanotubes with single-atomic-layer walls. Nature. 1993;363:605-607.

74. Chen B, Zhao X, Inoue S, Ando Y. Fabrication and dispersion evaluation of single-wall carbon nanotubes produced by $\mathrm{FH}$-arc discharge method. J Nanosci Nanotechnol. 2010;10(6):3973-3977.

75. Fan WW, LuYK, Bao WR, Zhao J, Fan BY. Preparation of coal-based carbon nanotube with $\mathrm{FeS}-\mathrm{Co}_{2} \mathrm{O}_{3}$ as catalyst. $J$ Mat Eng. 2008;10: 363-365.

76. Moshkalyov SA, Moreau ALD, Guttiérrez HR, Cotta MA, Swart JW. Carbon nanotubes growth by chemical vapor deposition using thin film nickel catalyst. Mater Sci Eng B. 2004;112:147-153.

77. Dikonimos Makris TH, Giorgi L, Giorgi R, et al. CVD synthesis of carbon nanotubes on different substrates. Nato Sci Ser II Math. 2006; 222:59-60.

78. Ren ZF, Huang ZW, Xu JW, et al. Synthesis of large arrays of well-aligned carbon nanotubes on glass. Science. 1998;282(5391):1105-1107.

79. Fan S, Chapline MG, Franklin NR, Tombler TW, Cassell AM, Dai HJ. Self-oriented regular arrays of carbon nanotubes and their field emission properties. Science. 1999;283(5401):512-514.

80. Nessim GD. Properties, synthesis, and growth mechanisms of carbon nanotubes with special focus on thermal chemical vapor deposition. Nanoscale. 2010;2:1306-1323.

81. Shinkai M, Yanase M, Honda H, Wakabayashi T, Yoshida J, Kobayashi T. Intracellular hyperthermia for cancer using magnetite cationic liposomes: in vitro study. Jpn J Cancer Res. 1996;87(11):1179-1183.

82. Yanase M, Shinkai M, Honda H, Wakabayashi T, Yoshida J, Kobayashi T. Intracellular hyperthermia for cancer using magnetite cationic liposomes: ex vivo study. Jpn J Cancer Res. 1997;88(7):630-632.

83. Yanase M, Shinkai M, Honda H, Wakabayashi T, Yoshida J, Kobayashi T. Intracellular hyperthermia for cancer using magnetite cationic liposomes: an in vivo study. Jpn J Cancer Res. 1998;89(4):463-469.

84. Ito $\mathrm{A}$, Shinkai $\mathrm{M}$, Honda $\mathrm{H}$, et al. Heat shock protein 70 expression induces antitumor immunity during intracellular hyperthermia using magnetite nanoparticles. Cancer Immunol Immunother. 2003; 52(2):80-88.

85. Ito A, Honda $\mathrm{H}$, Kobayashi $\mathrm{T}$. Cancer immunotherapy based on intracellular hyperthermia using magnetite nanoparticles: a novel concept of "heat-controlled necrosis" with heat shock protein expression. Cancer Immunol Immunother. 2006;55(3):320-328.

86. Le B, Shinkai M, Kitade T, et al. Preparation of tumor-specific magnetoliposomes and their application for hyperthermia. J Chem Eng Jpn. 2001;34(1):66-72. 
87. http://www.nanostart.de/en/news/press-releases/portfolio/ archive/2011/873-nanostart-holding-magforce-reimbursement-ofnanotherm-therapy.

88. Kost J, Noecker R, Kunica E, Langer R. Magnetically controlled release systems: effect of polymer composition. J Biomed Mater Res. 1985;19(8):935-940.

89. Edelman ER, Kost J, Bobeck H, Langer R. Regulation of drug release from polymer matrices by oscillating magnetic fields. J Biomed Mater Res. 1985;19(1):67-83.

90. Kumar CS, Mohammad F. Magnetic nanomaterials for hyperthermiabased therapy and controlled drug delivery. Adv Drug Deliv Rev. 2011;63(9):789-808.

91. Brazel CS. Magnetothermally-responsive nanomaterials: combining magnetic nanostructures and thermally-sensitive polymers for triggered drug release. Pharm Res. 2009;26(3):644-656.

92. Hoare T, Santamaria J, Goya GF, et al. A magnetically triggered composite membrane for on-demand drug delivery. Nano Lett. 2009;9(10): 3651-3657.

93. Behrens S, Bönnemann H, Matoussevitch N, et al. Air-stable Co-, Fe-, and Fe/Co-nanoparticles and ferrofluids. Phys Chem. 2006; 220(1):3-40.

94. Atai NA, Balaj L, Van Veen H, et al. Heparin blocks transfer of extracellular vesicles between donor and recipient cells. J Neurooncol. 2013;115:343-351.

95. Lu Z, Prouty MD, Guo Z, Golub VO, Kumar CS, Lvov YM. Magnetic switch of permeability for polyelectrolyte microcapsules embedded with Co@Au nanoparticles. Langmuir. 2005;21(5):2042-2050.

96. Zhang H, Pan D, Zou K, He J, Duan X. A novel core-shell structured magnetic organic-inorganic nanohybrid involving drug-intercalated layered double hydroxides coated on a magnesium ferrite core for magnetically controlled drug release. J Mater Chem. 2009;19:3069-3077.

97. Jain PK, El-Sayed IH, El-Sayed MA. Au nanoparticles target cancer. Nano Today. 2007;2(1):18-29.

98. Mehdizadeh A, Pandesh S, Shakeri-Zadeh, et al. The effects of folateconjugated gold nanorods in combination with plasmonic photothermal therapy on mouth epidermal carcinoma cells. Lasers Med Sci. Epub September 7, 2013.
99. Choi J, Yang J, Park J, et al. Specific near-IR absorption imaging of glioblastomas using integrin-targeting gold nanorods. Adv Funct Mater. 2011;21(6):1082-1088.

100. Fernandez Cabada T, de Pablo CS, Serrano AM, Guerrero Fdel P, Olmedo JJ, Gomez MR. Induction of cell death in a glioblastoma line by hyperthermic therapy based on gold nanorods. Intl J Nanomedicine. 2012;7:1511-1523.

101. Oli M. Aptamer conjugated gold nanorods for targeted nanothermal radiation of glioblastoma cancer cells. Young Sci J. 2010;3(8): 18-25.

102. Agarwal A, Mackey MA, El-Sayed MA, Bellamkonda RV. Remote triggered release of doxorubicin in tumors by synergistic application of thermosensitive liposomes and gold nanorods. ACS Nano. 2011;5(6): 4919-4926.

103. Xiao Y, Hong H, Matson VZ, et al. Gold nanorods conjugated with doxorubicin and cRGD for combined anticancer drug delivery and PET imaging. Theranostics. 2012;2(8):757-768.

104. Zhang Z, Wang L, Wang J, et al. Mesoporous silica-coated gold nanorods as a light-mediated multifunctional theranostic platform for cancer treatment. Adv Mater. 2012;24(11):1418-1423.

105. Fabbro C, Ali-Boucetta H, Da Ros T, Kostarelos K, Bianco A, Prato M. Targeting carbon nanotubes against cancer. Chem Commun. 2012;48(33):3911-3926.

106. Markovic ZM, Harhaji-Trajkovic LM, Todorovic-Markovic BM, et al. In vitro comparison of the photothermal anticancer activity of graphene nanoparticles and carbon nanotubes. Biomaterials. 2011;32(4): 1121-1129.

107. Wang CH, Chiou SH, Chou CP, Chen YC, Huang YJ, Peng CA. Photothermolysis of glioblastoma stem-like cells targeted by carbon nanotubes conjugated with CD133 monoclonal antibody. Nanomedicine. 2011;7(1):69-79.

108. Wang CH, Huang YJ, Chang CW, Hsu WM, Peng CA. In vitro photothermal destruction of neuroblastoma cells using carbon nanotubes conjugated with GD2 monoclonal antibody. Nanotechnology. 2009;20(31):315101.

109. Zonghuan L, Malcolm PD, Zhanhu G, et al. Magnestic switch of permeability for polyelectrolyte microcapsules embedded with nanoparticles. Langmuir. 2005;21:2042-2050.
International Journal of Nanomedicine

\section{Publish your work in this journal}

The International Journal of Nanomedicine is an international, peerreviewed journal focusing on the application of nanotechnology in diagnostics, therapeutics, and drug delivery systems throughout the biomedical field. This journal is indexed on PubMed Central,

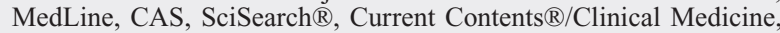

\section{Dovepress}

Journal Citation Reports/Science Edition, EMBase, Scopus and the Elsevier Bibliographic databases. The manuscript management system is completely online and includes a very quick and fair peer-review system, which is all easy to use. Visit http://www.dovepress.com/ testimonials.php to read real quotes from published authors. 